\title{
Simultaneous LC/MS Analysis of Hexachlorobenzene and Pentachlorophenol by Atmospheric Pressure Chemical Ionization (APCI) and Photoionization (APPI) Methods
}

\author{
Issey Osaka, ${ }^{*}$ Arifumi Yoshimoto, ${ }^{* *}$ Kazuyoshi NozaKI, $* *$ Hiroshi MoriwaKI, *** \\ Hideya KAWASAKI,** and Ryuichi ARAKAWA**i \\ *Center for Nano Materials and Technology, Japan Advanced Institute of Science and Technology, \\ 1-1 Asahidai, Nomi, Ishikawa 923-1294, Japan \\ **Department of Chemistry and Material Engineering, Kansai University, \\ 3-3-35 Yamate, Suita, Osaka 564-8680, Japan \\ ***Division of Applied Biology, Faculty of Textile Science and Technology, Shinshu University, \\ 3-15-1 Tokita, Ueda, Nagano 386-0567, Japan
}

\begin{abstract}
The simultaneous LC/MS analyses of hexachlorobenzene (HCB) and pentachlorophenol (PCP), two dioxin precursors were studied by both atmospheric pressure chemical ionization (APCI) and atmospheric pressure photoionization mass spectrometry (APPI/MS). The optimum LC/MS conditions of the simultaneous analysis were determined for these two compounds with different polarity. Ionization by APPI was found to be more effective than by APCI, and is thus a better ionization method for analysis of the two compounds. Using LC/APPI/MS we can achieve the simultaneous analysis of $\mathrm{HCB}$ and PCP at ppb levels.
\end{abstract}

(Received July 16, 2009; Accepted September 30, 2009; Published November 10, 2009)

\section{Introduction}

Most LC/MS analysis is recognized as being more suitable toward polar molecules than non-polar molecules. Mass spectrometric analysis by electrospray ionization (ESI) in particular often fails to detect low-polarity molecules. ${ }^{1}$ On the other hand, atmospheric pressure chemical ionization (APCI) and atmospheric pressure photoionization (APPI) can ionize less-polar molecules..$^{2-5}$

Low-polarity chemicals, such as persistent organic pollutants (POPs) are important subjects of environmental analysis. ${ }^{6-9}$ However, only a few analyses of these low-polarity environmental pollutants by LC/APCI/MS or by LC/APPI/MS have been reported. ${ }^{10}$ The simultaneous analysis of complex pesticide chemicals by LC/MS has become both popular and useful. ${ }^{11,12}$ Therefore, to establish an effective LC/MS analysis of low-polarity compounds is an important subject.

Persistent organic pollutants (POPs) were registered at the Stockholm Convention on Persistent Organic Pollutants (POPs) (2001) to reduce and eliminate them from products and facility emissions; hexachlorobenzene (HCB) and pentachlorophenol (PCP) were accredited as being one of the POPs. In addition, pentachlorobenzene (PCBz) was also added in May 2009. HCB and PCP are two major precursors of dioxin, and are important subjects in environmental analysis. ${ }^{13}$ They are produced with relatively high concentration, and are in proportion to the amount of emergence of dioxin. Therefore, they are frequently

$\dagger$ To whom correspondence should be addressed.

E-mail: arak@ipcku.kansai-u.ac.jp used as important markers in the operation and management of incinerators. Gas chromatography mass spectrometry (GC/MS) has been used for the analysis of HCB. ${ }^{14-17}$ On the other hand, since PCP is a high-polarity compound, derivatization is required for GC/MS analysis ${ }^{18-20}$ therefore, it is difficult to perform their simultaneous analyses by GC/MS.

LC/MS quantitative analysis of PCP has been known,,$^{21}$ but no HCB has been reported. Almost no quantitative LC/MS analysis of POPs has been reported. One of the reasons that only a few LC/APCI/MS or LC/APPI/MS studies are being carried out is due to their low detection sensitivities. However, a highly sensitive and simple method for the analysis of chlorothalonil was reported using LC/APPI/MS.22 Decomposition products of perfluorooctanesulfonic acid (PFOS) and their analogs were determined using ESI/MS. ${ }^{23}$ It is thus important to search for their better detection sensitivity of APCI and APPI toward low polarity molecules. For chlorinated aromatic compounds, a full description of substitution reactions under APCI processes has been studied by Dzidic et al. ${ }^{24}$ They reported that the phenoxide ions of $[\mathrm{M}-\mathrm{Cl}+\mathrm{O}]^{-}$in the negative APCI mass spectra are formed from chlorinated aromatic compounds via an intermediate complex of $\left[\mathrm{O}_{2} \cdot \mathrm{M}\right]^{-}$, where $\mathrm{M}$ represents a molecule.

It has been shown that $\mathrm{HCB}$ forms $\mathrm{m} / z 265$ of a $[\mathrm{M}-\mathrm{Cl}+\mathrm{O}]^{-}$ ion by both negative $\mathrm{APCI}^{24,25}$ and dopant-APPI ${ }^{26}$ where toluene was used as a dopant; however, their LC/MS were not developed. In the present work we searched for an optimum condition on HCB ionization in order to develop a simultaneous LC/MS analysis of $\mathrm{HCB}$ and $\mathrm{PCP}$, because the detected ions from $\mathrm{HCB}$ and PCP had the same $\mathrm{m} / \mathrm{z}$ values. 


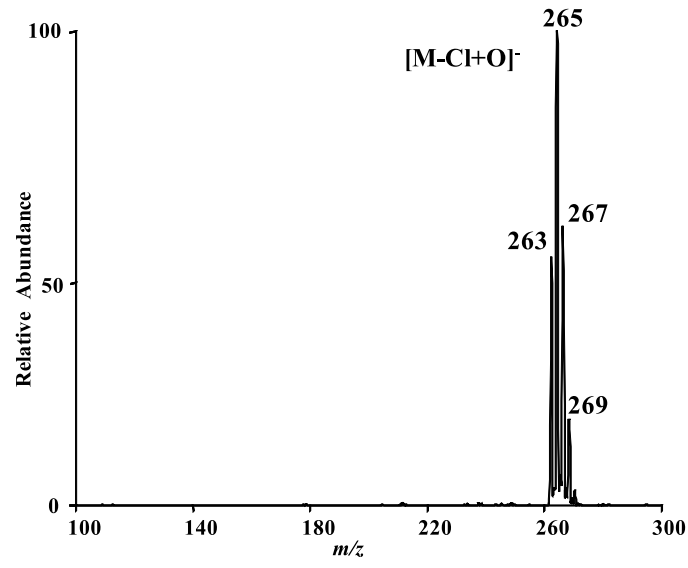

Fig. 1 APCI negative-ion mass spectrum of an HCB standard methanol solution $(10 \mu \mathrm{g} / \mathrm{mL})$.

\section{Experimental}

The APCI analysis was carried out with a LC/APCI/MS system (TSQ triple quadrupole MS, ThermoQuest) operated in a negative-ion mode. A capillary temperature of $200^{\circ} \mathrm{C}$, a desolvation temperature of $150^{\circ} \mathrm{C}$, and a corona discharge current of $5 \mu \mathrm{A}$ were used. Fifty microliters of a sample were introduced and the flow rate of a mobile phase was $0.3 \mathrm{~mL} / \mathrm{min}$. LC separation was performed with an Inertsil ODS-P column $(2.1 \times 150 \mathrm{~mm}$, GL Science, Tokyo, Japan). The mobile phase used was methanol.

An APPI analysis was performed by connecting a prototype photoionization source with LC/MS (API2000, Applied Biosystems) in a negative-ion mode. The ion spray voltage, $-1280 \mathrm{~V}$; curtain gas flow, $10 \mathrm{psi}$; lamp gas flow, $2.0 \mathrm{~L} / \mathrm{min}$; drift voltage, $-30 \mathrm{~V}$ were used. A dopant of toluene was introduced at $10 \mu \mathrm{L} / \mathrm{min}$. LC separation was carried out by L-column ODS $(2.1 \times 150 \mathrm{~mm}$, Chemicals Evaluation and Research Institute, Tokyo, Japan). The mobile phase used was A (methanol) and B (1 mM ammonium acetate and $1 \mathrm{~mL} / \mathrm{L}$ acetatic acid in $\mathrm{H}_{2} \mathrm{O}$ ) using a gradient program from $50 \%$ A to $90 \% \mathrm{~A}(0-5 \mathrm{~min})$ and holding at $90 \% \mathrm{~A}(5-15 \mathrm{~min})$. HCB was obtained from GL Science (Tokyo, Japan) and hexachlorobenzene(HCB) $-{ }^{13} \mathrm{C}_{6}$ was from Wako Pure Chemicals (Osaka, Japan). PCP, pentachlorobenzene (PCBz), 1,2,4,5-tetrachlorobenzene, and 1,2,3,4-tetrachlorobenzene were purchased from Tokyo Kasei (Tokyo, Japan). Methanol of HPLC grade was used (Wako Pure Chemicals). $\mathrm{HCB}-{ }^{13} \mathrm{C}_{6}$ was dissolved in $25 \mathrm{mg} / \mathrm{mL}$, and $10 \mu \mathrm{L}$ was introduced into $1 \mathrm{~mL}$ of a HCB solution to use as an internal standard. The calibration curve was formed from the areas of SIM ions divided by that of $\mathrm{HCB}-{ }^{13} \mathrm{C}_{6}$. The detection limit was obtained with the concentration having $S / N=3$.

\section{Results and Discussion}

\section{$A P C I / M S$}

Figure 1 is the APCI negative-ion mass spectrum of an HCB standard methanol solution $(10 \mu \mathrm{g} / \mathrm{mL})$. $\left[\mathrm{M}-\mathrm{Cl}+\mathrm{O}^{-}\right.$was the only ion detected. The MS/MS of the base peak $\mathrm{m} / \mathrm{z} 265$ generates a single ion of $\mathrm{Cl}^{-}$at $\mathrm{m} / z$ 35. However, this product ion was too weak to be used for MS/MS analysis. The isotope $\mathrm{HCB}^{-13} \mathrm{C}_{6}$ also results in a $[\mathrm{M}-\mathrm{Cl}+\mathrm{O}]^{-}$ion at $\mathrm{m} / z, 271$. In the

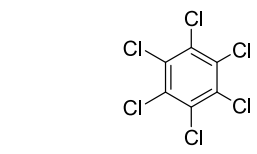

$[\mathrm{M}-\mathrm{Cl}+\mathrm{O}]^{-}: \quad 1$

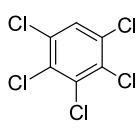

0.29

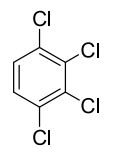

0.014

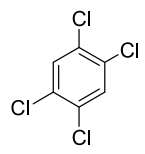

Fig. 2 Relative ion intensities of $[\mathrm{M}-\mathrm{Cl}+\mathrm{O}]^{-}$for $\mathrm{HCB}, \mathrm{PCBz}$, 1,2,3,4-tetrachlorobenzene and 1,2,4,5-tetrachlorobenzene by APCI/MS.

case of $\mathrm{PCP}$ and $\mathrm{PCBz}$, the ions $[\mathrm{M}-\mathrm{H}]^{-}$and $[\mathrm{M}-\mathrm{Cl}+\mathrm{O}]^{-}$were observed at $\mathrm{m} / \mathrm{z}, 265$ and 231, respectively.

We studied the effect of the water content in a mobile phase on the APCI ionization of $\mathrm{HCB}$, and found that the ion intensity started to decrease after the water content increased above $10 \%$. This might have been due to the formation of a radical anion $\left(\mathrm{O}_{2}^{--}\right)$by corona discharge. The $\mathrm{O}_{2}^{-\cdot}$ radical anion reacted with water to form a stable cluster of $\left(\mathrm{H}_{2} \mathrm{O}\right)_{\mathrm{n}} \mathrm{O}_{2}^{--}$, which interferes in the substitution reaction of chlorine with oxygen..$^{24,25}$ In order to gain further evidence on the prediction of water cluster formation, we used methanol/ $\mathrm{H}_{2} \mathrm{O}(1: 1)$ for the mobile phase and $\mathrm{CO}_{2}$ for a sheath gas; we found that the intensity of $[\mathrm{M}-\mathrm{Cl}+\mathrm{O}]^{-}$increased by approximately two fold. This increase in the ion intensity might have been due to the reaction between the $\left(\mathrm{H}_{2} \mathrm{O}\right)_{\mathrm{n}} \mathrm{O}_{2}^{-\cdot}$ cluster and $\mathrm{CO}_{2}$ to release $\mathrm{O}_{2}^{--}$. However, the ion intensity is still too small, only about one half of that using $100 \%$ methanol as the mobile phase.

In order to examine the effect on a substitution reaction of $\mathrm{HCB}$, we studied the APCI spectra of PCBz, 1,2,3,4tetrachlorobenzene and 1,2,4,5-tetrachlorobenzene. The results showed that both $\mathrm{PCBz}$ and 1,2,3,4-tetrachlorobenzene gave the $[\mathrm{M}-\mathrm{Cl}+\mathrm{O}]^{-}$ion as was obtained with $\mathrm{HCB}$; but no assignable ions could be detected on 1,2,4,5-tetrachlorobenzene. The different relative intensities of $[\mathrm{M}-\mathrm{Cl}+\mathrm{O}]^{-}$were obtained as shown in Fig. 2.

Dzidic et al..$^{24}$ measured penta, tetra, tri and dichlorobenzene, and showed that the APCI ion intensities of substitution decrease with a decreasing number of chlorine atoms. In the nucleophilic reaction of aromatic compounds, it is known that more electron-withdrawing chlorine substitutions will stabilize the carbocation intermediate and increase the reactivity. In addition, electron-withdrawing substituents at the ortho- or para-position will have a higher reactivity to the attacking nucleophile. The differences in the ion intensities that we observed in 1,2,3,4-tetrachlorobenzene and 1,2,4,5-tetrachlorobenzene could be due to the above-mentioned substitution effects.

Using an isocratic elution with methanol as the mobile phase, an APCI mass chromatogram was obtained, as shown in Fig. 3. The detection limits were not acceptable to be $10 \mathrm{ng} / \mathrm{mL}$ for HCB and PCP. In addition, PCP was poorly retained by the column (1.54 min), which would be difficult to separate from another matrix to achieve a successful analytical separation.

\section{Dopant APPI/MS}

Figure 4 shows the dopant APPI/MS spectrum of the HCB standard solution $(10 \mu \mathrm{g} / \mathrm{mL})$ introduced from a syringe pump. Similar to APCI/MS, the $\left[\mathrm{M}-\mathrm{Cl}+\mathrm{O}^{-}\right.$ion was detected. The MS/MS of $m / z 265$ gave a single product ion of $\mathrm{m} / z, 35\left(\mathrm{Cl}^{-}\right)$. The ion intensity was also too low to be applied as a practical MS/MS analysis. $\mathrm{HCB}_{-13}{ }^{13} \mathrm{C}_{6}$ gave the same $[\mathrm{M}-\mathrm{Cl}+\mathrm{O}]^{-}$ion at $m / z$ 271. $\mathrm{PCP}$ and $\mathrm{PCBz}$ gave a $[\mathrm{M}-\mathrm{H}]^{-}$and $[\mathrm{M}-\mathrm{Cl}+\mathrm{O}]^{-}$ion at $m / z 265$ and 231, respectively, by APPI ionization.

When toluene was not used as a dopant, we could not detect 


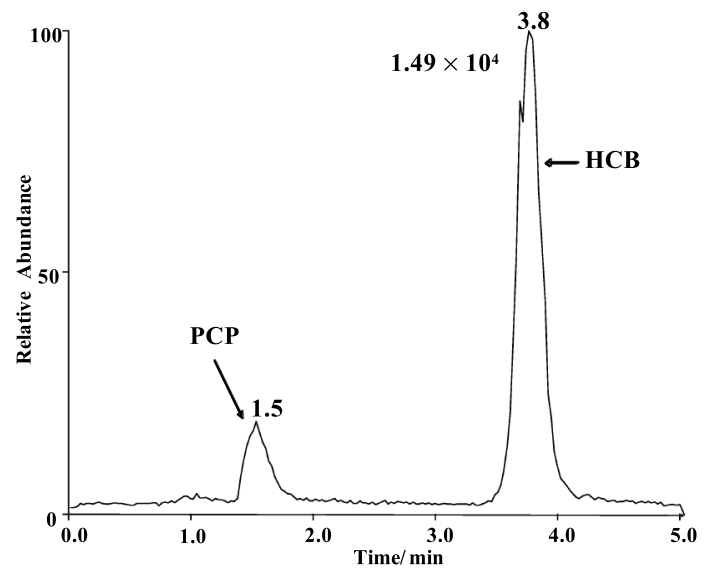

Fig. 3 LC/APCI/MS ion chromatogram of HCB and PCP $(50 \mathrm{ng} / \mathrm{mL}$ each).

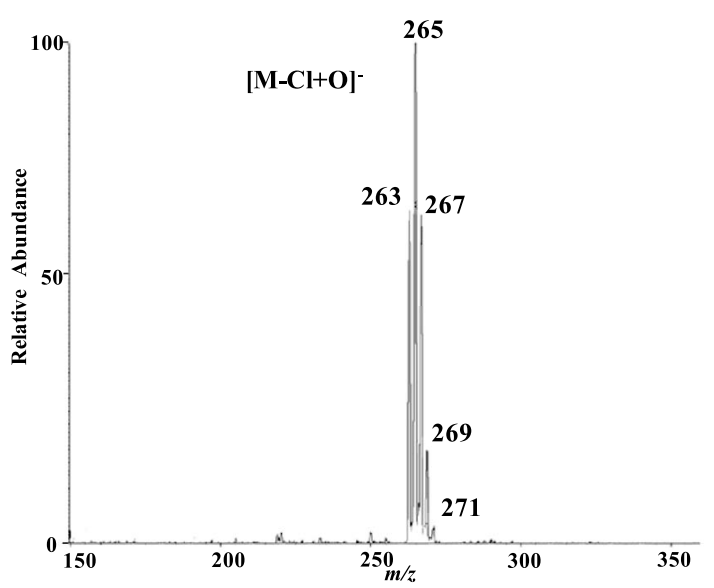

Fig. 4 Dopant APPI/MS spectrum of the HCB standard solution $(10 \mu \mathrm{g} / \mathrm{mL})$.

any ion peak that correlates with HCB in the APPI spectra. We also found that the ion intensity of $[\mathrm{M}-\mathrm{Cl}+\mathrm{O}]^{-}$did not decrease by increasing the water content of the mobile phase, even up to $50 \%$. Namely, a radical cation of dopant toluene is formed by photo ionization, releasing an electron. ${ }^{26}$ This electron is trapped by an oxygen molecule in the system to produce an oxygen radical anion. The oxygen radical anion can easily attract the toluene radical cation bound to HCB through a $\pi-\pi$ interaction between $\mathrm{HCB}$ and the toluene radical cation; thus, the substitution is enhanced to produce $[\mathrm{M}-\mathrm{Cl}+\mathrm{O}]^{-}$. Because of the above-mentioned interaction, the oxygen radical anion become less likely to participate in cluster formation with water, as indicated by no decrease in the intensity by water addition, which resulted in an effective nucleophilic substitution with HCB. Mass chromatograms of HCB and PCP are shown in Fig. 5. Both PCP and HCB are well separated with sufficient retention in the LC column. The calibration curve (Fig. 6) was obtained in the $10-500 \mathrm{ng} / \mathrm{mL}$ range, and a good linearity $\left(r^{2}>0.99\right)$ was obtained. Therefore, LC/APPI/MS can provide an effective simultaneous analysis of $\mathrm{HCB}$ and PCP at ppb levels.

In conclusion, LC/APCI/MS and LC/APPI/MS analyses of $\mathrm{HCB}$ and PCP were conducted. The APCI ion intensity of HCB decreases with an increase in the water content of the LC mobile

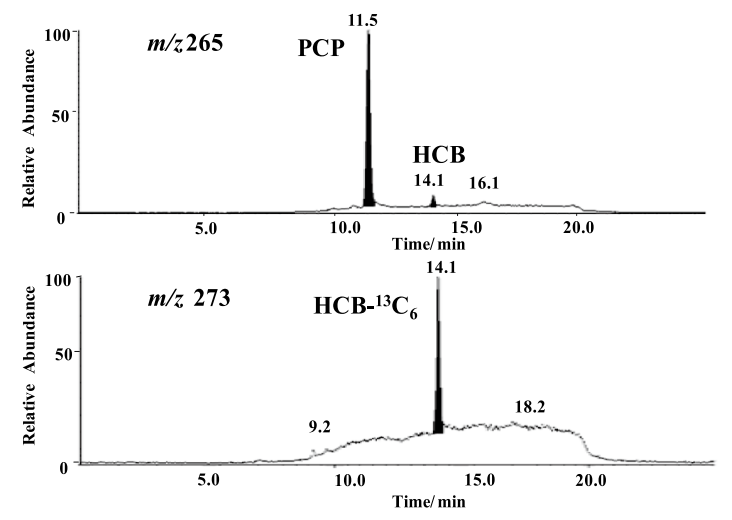

Fig. 5 LC/APPI/MS ion chromatograms of $\mathrm{HCB}$ and $\mathrm{PCP}$ $(100 \mathrm{ng} / \mathrm{mL}$ each).
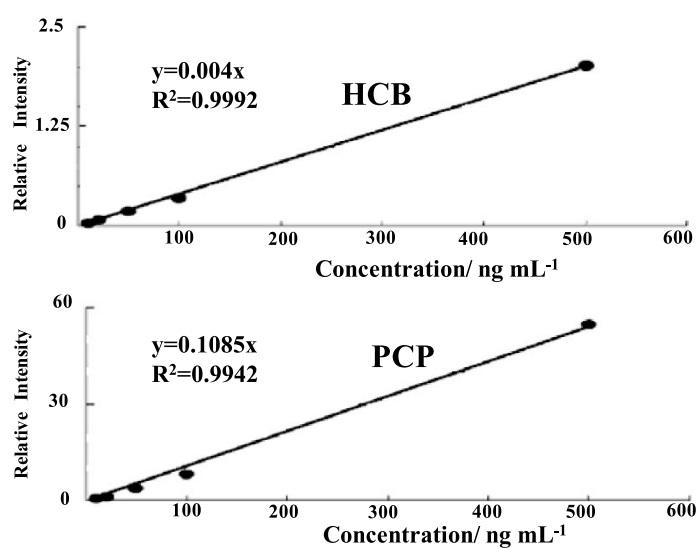

Fig. 6 Calibration curves of simultaneous LC/APPI/MS analysis for $\mathrm{HCB}$ and $\mathrm{PCP}\left(\mathrm{HCB}-{ }^{13} \mathrm{C}_{6}\right.$ as the internal standard).

phase; on the contrary, a decrease upon the water addition is not significant in LC/APPI/MS. The difference is due to the mechanism of HCB ionization in the two ionization methods. In LC/APCI/MS, satisfactory chromatographic column retention and separation of HCB and PCP can not be achieved, because an additional water content in the mobile phase would cause a large decrease in the ion intensity. On the other hand, LC/APPI/MS can achieve sufficient retention and separation. Therefore, it is concluded that dopant APPI is a more suitable LC/MS method for the simultaneous analysis of HCB and PCP. The APPI method reported here should be useful to apply for the onside analysis of HCB and PCP at incinerators. Further study on the ionization in the presence of different and complex matrix or backgrounds may be required.

\section{Acknowledgements}

This work was partially supported by a Grant-in-Aid for Scientific Research (B) and by the Strategic Project to Support the Formation of Research Bases at Private Universities: Matching Fund Subsidy from MEXT.

\section{References}

1. S. J. Gaskell, J. Mass Spectrom., 1997, 32, 677. 
2. M. Holčapek, K. Volná, and D. Vanĕrková, Dyes Pigm., 2007, 75, 156.

3. M. Ohta, N. Kawakami, S. Yamato, and K. Shimada, J. Pharm. Biomed. Anal., 2003, 30, 1759.

4. H. Hayen and U. Karst, J. Chromatogr., A, 2003, 1000, 549.

5. D. B. Robb, T. R. Covey, and A. P. Bruins, Anal. Chem., 2000, 72,3653 .

6. S. Tanabe and T. Kunisue, Environ. Pollut., 2007, 146, 400.

7. R. Kucklick, W. D. J. Struntz, P. R. Becker, G. W. York, T. M. O'Hara, and J. E. Bohonowych, Sci. Total Environ., 2002, 287, 45 .

8. J. M. Pacyna, K. Breivik, J. Munch, and J. Fudala, Atmos. Environ., 2003, 37(Supple. 1), S119.

9. S. V. Kakareka, Atmos. Environ., 2002, 36, 1407.

10. H. Moriwaki, Curr. Org. Chem., 2005, 9, 849.

11. L. Alder, K. Greulich, G. Kempe, and B. Vieth, Mass Spectrom. Rev., 2006, 25, 838 .

12. A. Kloepfer, J. B. Quintana, and T. Reemtsma, $J$. Chromatogr., A, 2005, 1067, 153.

13. S. Sakai, Y. Hirai, and H. Takatsuki, J. Jpn. Soc. Waste Management, 2001, 12, 349.

14. P. M. Quinsey, D. C. Donohue, and J. T. Ahokas, Food Chem. Toxicol., 1995, 33, 49.

15. D. C. G. Muir, N. P. Grift, W. L. Lockhart, P. Wilkinson, B. N. Billeck, and G. J. Brunskill, Sci. Total Environ., 1995, 160/161, 447.

16. D. L. Torre, A. I. Fernandez, C. Tarazona, J. V. Mufioz, and
M. J. Mufioz, Chemosphere, 1995, 31, 2727.

17. D. Andrzejewski and A. Weisz, J. Chromatogr., A, 1999, 863, 37.

18. M. Kawaguchi, N. Sakui, N. Okanouchi, R. Ito, K. Saito, S. Izumi, T. Makino, and H. Nakazawa, J. Chromatogr., B, 2005, 820, 49 .

19. M. Kawaguchi, Y. Ishii, N. Sakui, N. Okanouchi, R. Ito, K. Saito, and H. Nakazawa, Anal. Chim. Acta, 2005, 533, 57.

20. R. Bravo, L. M. Caltabiano, C. Fernandez, K. D. Smith, M. Gallegos, R. D. Whitehead Jr, G. Weerasekera, P. Restrepo, A. M. Bishop, J. J. Perez, L. L. Needham, and D. B. Barr, J. Chromatogr., B, 2005, 820, 229.

21. A. Oubina, D. Puig, J. Gasón, and D. Barceló, Anal. Chim. Acta, 1997, 346, 49

22. A. Yamamoto, I. Miyamoto, M. Kitagawa, H. Moriwaki, H. Miyakoda, H. Kawasaki, and R. Arakawa, Anal. Sci., 2009, 25, 693.

23. H. Hori, Y. Nagaoka, A. Yamamoto, T. Sano, N. Yamashita, S. Taniyasu, S. Kutsuna, I. Osaka, and R. Arakawa, Environ. Sci. Technol., 2006, 40, 1049.

24. I. Dzidic, D. I. Carroll, R. N. Stillwell, and E. C. Horning, Anal. Chem., 1975, 47, 1308.

25. B. A. Thomson, W. R. Davidson, and A. M. Lovett, Environ Health Perspect., 1980, 36, 77.

26. T. J. Kauppila, T. Kotiaho, R. Kostiainen, and A. P. Bruins, J. Am. Soc. Mass Soc., 2004, 15, 203 